\title{
Caracterización bacteriológica en lagunas de irrigación y la relación con el índice de infestación larvaria por Anopheles albimanus
}

Arnold Enrique Houghton Cuevas ${ }^{1}$

Héctor Escalante ${ }^{2}$

\section{RESUMEN}

El objetivo del estudio fue establecer la relación de la contaminación bacteriológica de la materia orgánica de las lagunas de irrigación y el índice de infestación larvaria por Anopheles albimanus; lo cual es una herramienta para el monitoreo del control vectorial en fase acuática.

El tipo de estudio es descriptivo transversal con el cálculo estadístico del coeficiente de correlación de Pearson ( $r$ ). Se tomaron muestras de agua de las lagunas de irrigación para establecer dos elementos; uno de ellos, fue la determinación de la contaminación por coliformes totales, coliformes fecales y Escherichia coli. También, determinamos el índice de infestación larvaria por Anopheles albimanus, de acuerdo a los estándares internacionales (PAHO/WHO).

Existen algunos factores (luz solar, temperatura, concentración de sal, etc.) en el biotopo del mosquito, que intervienen en el ciclo biológico de estos.

Las 8 lagunas de irrigación fueron la unidad de observación. En todas se detectó una alta contaminación bacteriológica por coliformes totales, coliformes fecales y Escherichia coli. El coeficiente de correlación de Pearson resultó cercano a cero, por lo tanto, no existe relación entre la contaminación bacteriológica y el índice de infestación larvaria por Anopheles albimanus.

Palabras clave: malaria, bacterias, Anopheles, coliformes, lagunas.

1 Estudiante, Posgrado en Salud Pública, UNAH: houghtoncuevas@yahoo.com

2 Profesor universitario y asesor, Posgrado en Salud Pública, UNAH: escalanteh.@gmail.com 


\section{ABSTRACT}

The purpose of this study was to establish the relationship of the bacteriologic contamination by organic matter of the irrigation pond and the infestation larval index of Anopheles albimanus; a tool for monitoring the vector control in aquatic phase.

The type of study is transverse descriptive with statistic calculating of correlation coefficient of Pearson. It taked water samples of the pont, to for establish two elements, one of them, was to determine the contamination for total coliform, fecal coliform and Escherichia coli. In the other, we determined the infestation larval index of Anopheles albimanus, according to International Standards (PAHO/WHO).

8 irrigation pounds, were monitored in this study. In all of them, we detected a high bacteriologic contamination by total coliform, fecal coliform and Escherichia coli. The correlation coefficient of Pearson between the study's variable was near to cero, suitable, there was no relationship of the bacteriologic contamination and the infestation larval index of Anopheles albimanus.

There are many factors (sunlight, temperature, salt concentration, etc.) in the biotope of the mosquitoes that have an intervention in the biologic cycle of them.

Key words: malaria, bacterium, Anopheles, coliform, gaps. 


\section{INTRODUCCIÓN}

La malaria se constituye en el cuarto ítem de la llamada "agenda inconclusa", se denomina así porque la labor de los países latinoamericanos, en lo que respecta a la atención primaria en salud, seguía inconclusa al comenzar el nuevo milenio. Esta enfermedad es producto de varios factores relacionados con el hospedero y con el parásito. También ha sido reconocido que su transmisión es sensible al clima y el ambiente, percibiéndose como la enfermedad metaxénica más propensa a ser afectada por los cambios climáticos globales. Por lo tanto, la solución del problema no se logrará por una sola actividad o medida independiente, de forma que es importante el manejo de las variables humanas y técnicas, en lo particular el desarrollo social, evitando el deterioro en la salud y calidad de vida de la población.

En esta investigación se aportan elementos para el análisis del abordaje de la transmisión de la malaria, específicamente profundiza el conocimiento sobre los factores que intervienen en el ciclo biológico del vector transmisor. Asimismo, este análisis es propicio para generar elementos importantes en la promulgación de estrategias y elementos importantes en la construcción de políticas públicas en el abordaje de esta enfermedad.

Se ha determinado que la flora microbiana asociada con el detritus orgánico puede ser extremadamente importante en la nutrición de los animales filtradores que habitan un sistema acuático (Velasquez y Miserendino, 2003). Algunos estudios han sugerido que las descargas superficiales a los cuerpos receptores de agua pueden lograr incrementar las poblaciones de organismos filtradores presentes en ellos, tal como es el comportamiento de las larvas del mosquito transmisor de la malaria. Como objetivo de este trabajo, se especifica el establecimiento de la relación del índice de infestación larvario del Anopheles albimanus y la contaminación bacteriológica por coliformes totales, coliformes fecales y Escherichia coli en las lagunas de irrigación.

\section{MATERIALES Y MÉTODO}

El estudio es del tipo descriptivo transversal de asociación, cuya unidad de análisis son los reservorios de aguas (lagunas) que se han convertido en focos de desarrollo del ciclo biológico del mosquito transmisor de la malaria. El cálculo estadístico del coeficiente de correlación define la fuerza de la relación lineal entre dos variables que 
fueron objetos del presente estudio (índice de infestación larvaria por Anopheles albimanus y cantidad de bacterias coliformes).

El análisis bivariado se hizo a través de la regresión lineal simple en donde la exposición a la contaminación (coliformes totales / coliformes fecales / Escherichia coli) y el desenlace en el índice de infestación larvaria determinan la asociación por medio de un coeficiente de correlación de Pearson (r).

El universo de esta investigación fueron todas las lagunas de irrigación que se encuentran en el Centro de Entrenamiento y Desarrollo Agrícola (CEDA), dependencia de la Secretaría de Agricultura (SAG), ubicado en el municipio de Comayagua, departamento de Comayagua. La muestra fue por conveniencia: 11 cuerpos de agua permanentes (lagunas para irrigación) ubicadas dentro de un perímetro de 25 manzanas de tierra que son propiedad de dicho centro de entrenamiento. De estas 11 lagunas de irrigación que reciben agua del río Selguapa y que poseen los criterios de inclusión (con lecho y periferia de tierra), solamente pudieron ser monitoreadas 8 , ya que las 3 restantes se encontraban sin agua al momento de nuestro monitoreo.

El procesamiento de muestras y la recolección de la información se hicieron previa capacitación del personal de laboratorio y campo de la Región Sanitaria de Comayagua, a través de instrumentos de observación y de medición para el cálculo de los índices. Es de hacer notar que el inconveniente de no haber podido incluir mediciones en los cuerpos de agua (tales como pH, temperatura, etc.) produjo un sesgo de información, con el objeto de que al incorporarse al presente estudio hubiesen podido enriquecer esta investigación.

La metodología de muestreo en los cuerpos de agua para determinar la densidad larvaria es la que recomienda la Organización Mundial de la Salud (OMS), utilizando un cucharón de $250 \mathrm{~cm} 3$, el cual se sumerge 3 veces cada 10 metros en un área de 1 metro cuadrado.

Para la determinación del índice de infestación larvaria por Anopheles albimanus en campo, se realizó una toma de muestra a la derecha, otra a la izquierda y una al centro; dirigiéndolas si no hay vegetación en la unión agua suelo con un movimiento de succión con el deeper y no por rebosamiento. Los hallazgos entomológicos de las caladas tomadas se reportaron en el formato de pesquisa larvaria EN-2, registrando las larvas que se observaron en cada una de ellas (I, II, III, IV estadio y pupas). 
El cálculo de los índices larvarios por metro cuadrado, tanto joven, maduro y absoluto, se hizo a través de la razón matemática entre las larvas de los diferentes estadios encontradas en las cucharonadas tomadas multiplicadas por el factor 100.

La toma de muestras de agua para la determinación de los parámetros microbiológicos, siguió el siguiente proceso:

1. Se realizaron 4 tomas de muestras de agua, referenciadas al norte, sur, este y oeste de cada laguna; sumergiendo el deeper a $30 \mathrm{~cm}$ de la superficie del mismo lugar de la captura de las larvas del mosquito, evitando incluir como parte de dichas muestras las larvas y pupas del vector.

2. La cantidad de muestra fue de una porción mínima de $100 \mathrm{ml}$, colocándose en una bolsa de plástico estéril sin tiosulfato de sodio (ya que esta sustancia solamente se usa para bloquear la acción del cloro cuando se supone que este está presente en las muestras de agua).

3. La muestra se rotuló con los datos de la laguna de procedencia, se refrigeró en termos portátiles (2 a 6 grados Celsius) y se trasladó al laboratorio de la Región Sanitaria Departamental de Comayagua para realizar los análisis microbiológicos de los parámetros coliformes totales, coliformes fecales y Escherichia coli, mediante la técnica descrita por la literatura del Standard Methods for the Examination of Water and Wastewater.

En la realización de los análisis microbiológicos de las muestras de agua se siguieron estos pasos:

1. Con un paño humedecido con fenol al $1 \%$, se realizó el proceso de desinfección de la superficie de trabajo, esperando que secara dicha superficie.

2. Se enciende un mechero bunsen o alcohol en el mesón de trabajo.

3. Se extrajeron las placas de petrifilm MR del contenedor laminado refrigerado a temperatura ambiente, por lo menos 10 minutos antes del sembrado de las muestras.

4. Las placas de petrifilm se rotularon con los datos siguientes: número de la laguna, orientación cardinal (norte, sur, este, oeste), hora de la toma de muestra, fecha 
de la toma muestra y responsable de la toma de muestra.

5. Con una jeringa estéril de un (1) mililitro, sin aguja, se extrajo la totalidad de su capacidad con el agua de la muestra de la laguna respectiva.

6. Se levantó el protector de la placa petrifilm y se vierte el contenido de la jeringa en el medio mencionado.

7. Se colocó la placa sembrada con el agua problema en la incubadora a 37 grados Celsius y se mantuvo en ese lugar por 24 horas.

8. Se extrajeron las placas de la incubadora y con un marcador indeleble punto fino se hacen los recuentos de colonias según las características siguientes:

a. Coliformes totales: colonias de color rosado sin halo de gas a su alrededor.

b. Coliformes fecales: colonias de color rosado con halo de gas a su alrededor.

c. Escherichia coli: colonias de color azul con halo de gas a su alrededor.

9. De cada laguna se sacó el promedio de cada parámetro microbiológico tomando en cuenta las placas de petrifilm por orientación cardinal y se reporta en el formato respectivo.

\section{RESULTADOS}

El procedimiento metodológico, explicado anteriormente, se realizó en su totalidad, tomando para ello la experiencia del personal de la Sección de Entomología de la Región Sanitaria Departamental de Comayagua, así como del laboratorio de esta institución para realizar la presente investigación.

1. El gráfico 1 revela la dispersión de las correlaciones entre los datos del índice de infestación larvaria (\%) de Anopheles albimanus y el hallazgo de las Unidades formadoras de colonias de coliformes totales en las 8 lagunas monitoreadas en la presente investigación. 
Gráfico 1. Correlación lineal entre índice de infestación larvaria por Anopheles albimanus de las lagunas investigadas y la contaminación microbiológica por coliformes totales, septiembre de 2011

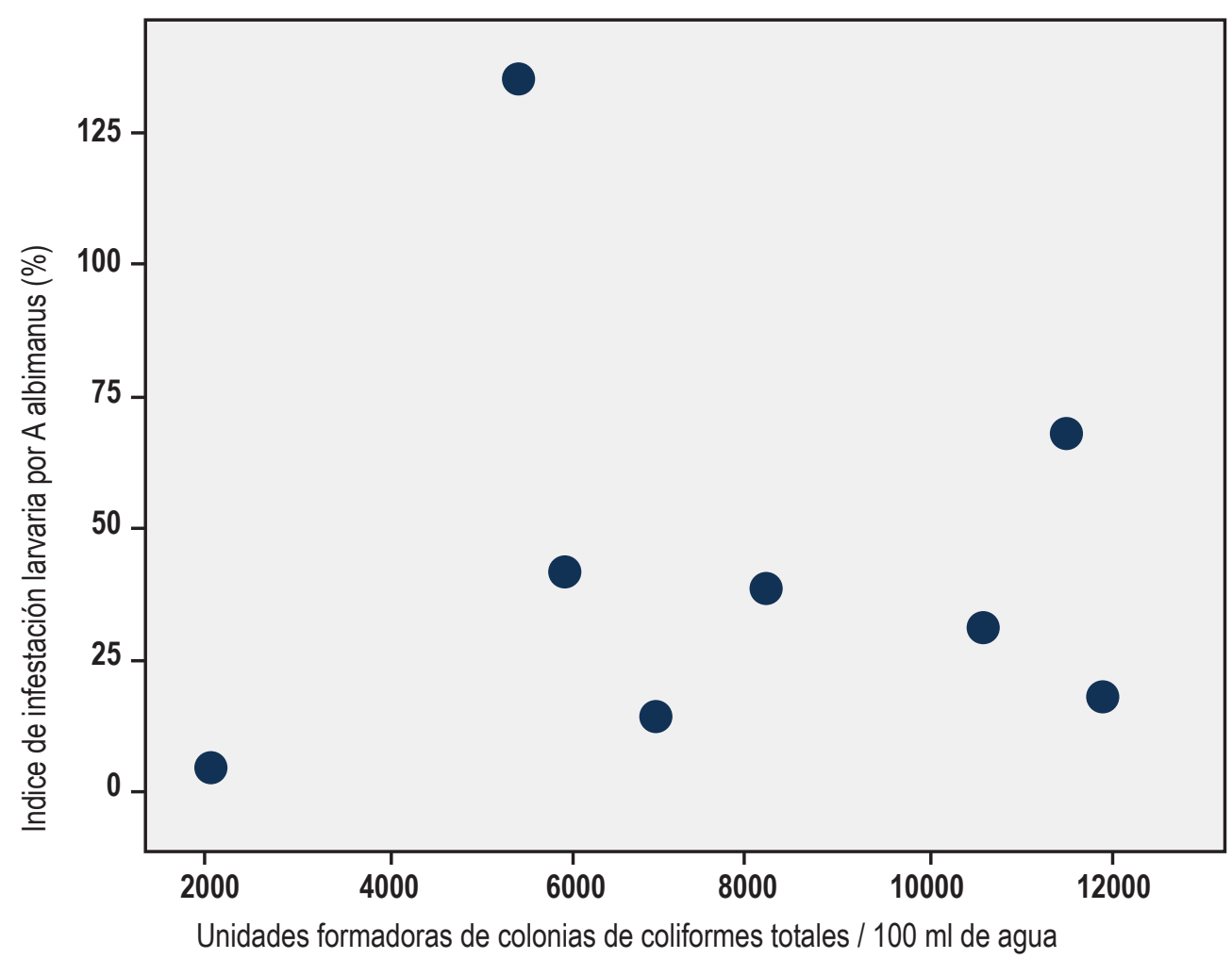

Fuente: hoja de resultados de programa estadístico SPSS (versión 18).

2. El gráfico 1 muestra un agrupamiento hacia la derecha inferior de las correlaciones entre los datos del índice de infestación larvaria (\%) de Anopheles albimanus y el hallazgo de las unidades formadoras de colonias de coliformes totales en las 8 lagunas monitoreadas en la presente investigación (resultados), lo que muestra que los diferentes grados de contaminación orgánica por coliformes totales (mayores a 6,000 UFC), se circunscriben a índices de infestación larvaria (\%) por Anopheles albimanus menores al $70 \%$. 
Gráfico 2. Correlación lineal entre el índice de infestación larvaria por Anopheles albimanus de las lagunas investigadas y la contaminación microbiológica por coliformes fecales, septiembre de 2011

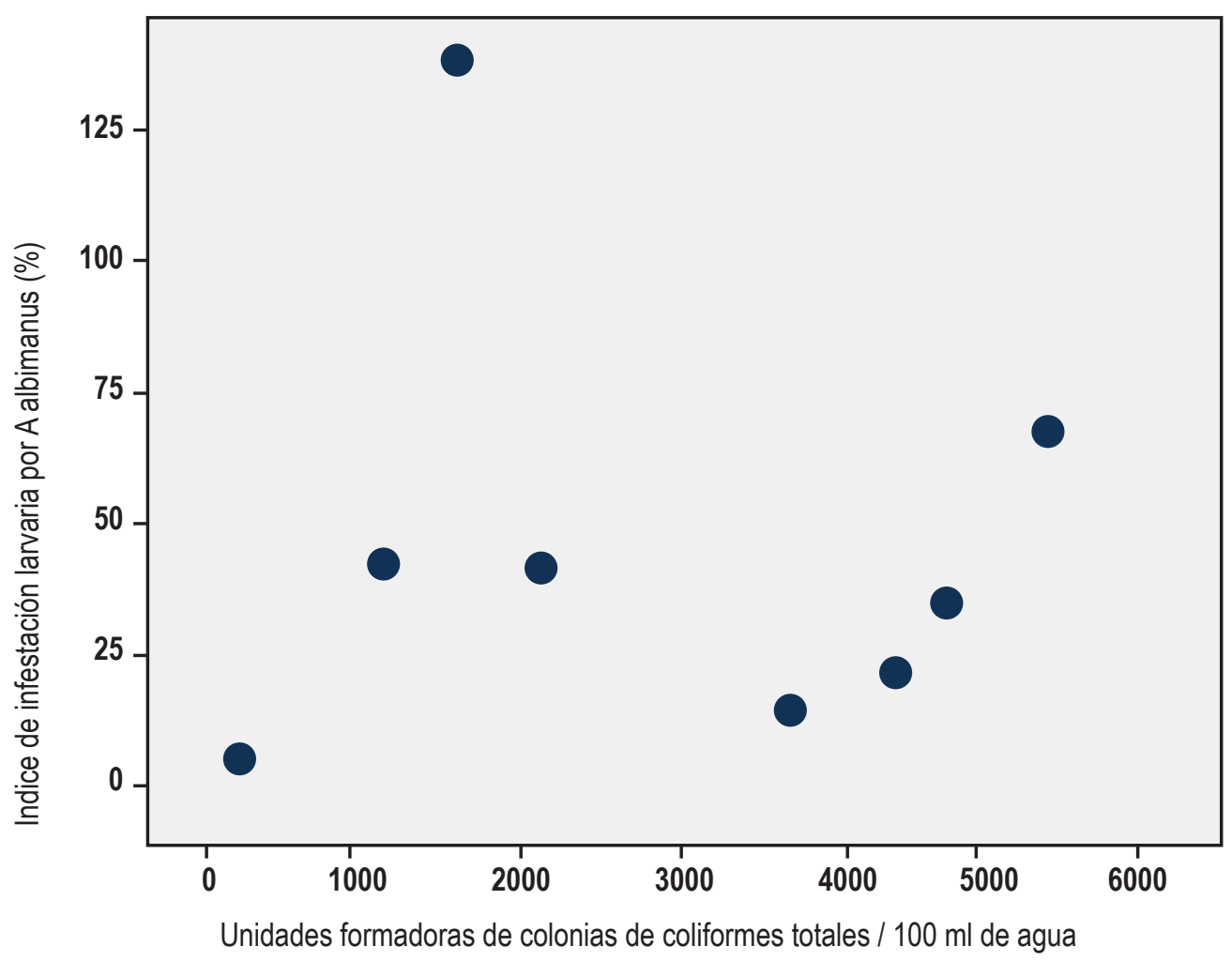

Fuente: hoja de resultados de programa estadístico SPSS (versión 18).

3. El gráfico 2 revela la dispersión de las correlaciones entre los datos del índice de infestación larvaria (\%) de Anopheles albimanus y el hallazgo de las unidades formadoras de colonias de coliformes fecales en las 8 lagunas monitoreadas en la presente investigación, lo que muestra en forma general que no existe una relación directa entre las dos variables anteriormente mencionadas.

4. El gráfico 2 muestra una dispersión heterogénea en el nivel inferior de las correlaciones entre los datos del índice de infestación larvaria (\%) de Anopheles albimanus y el hallazgo de las unidades formadoras de colonias de coliformes totales en las 8 lagunas monitoreadas en la presente investigación. A excepción 
de una laguna, el comportamiento del número de coliformes fecales varían de forma indistinta (mayor o menor), siempre relacionado condice de infestación larvaria por Anopheles albimanus menor del $70 \%$.

Gráfico 3. Correlación lineal entre el índice de infestación larvaria por Anopheles albimanus de las lagunas investigadas y la contaminación microbiológica por Escherichia coli, septiembre de 2011

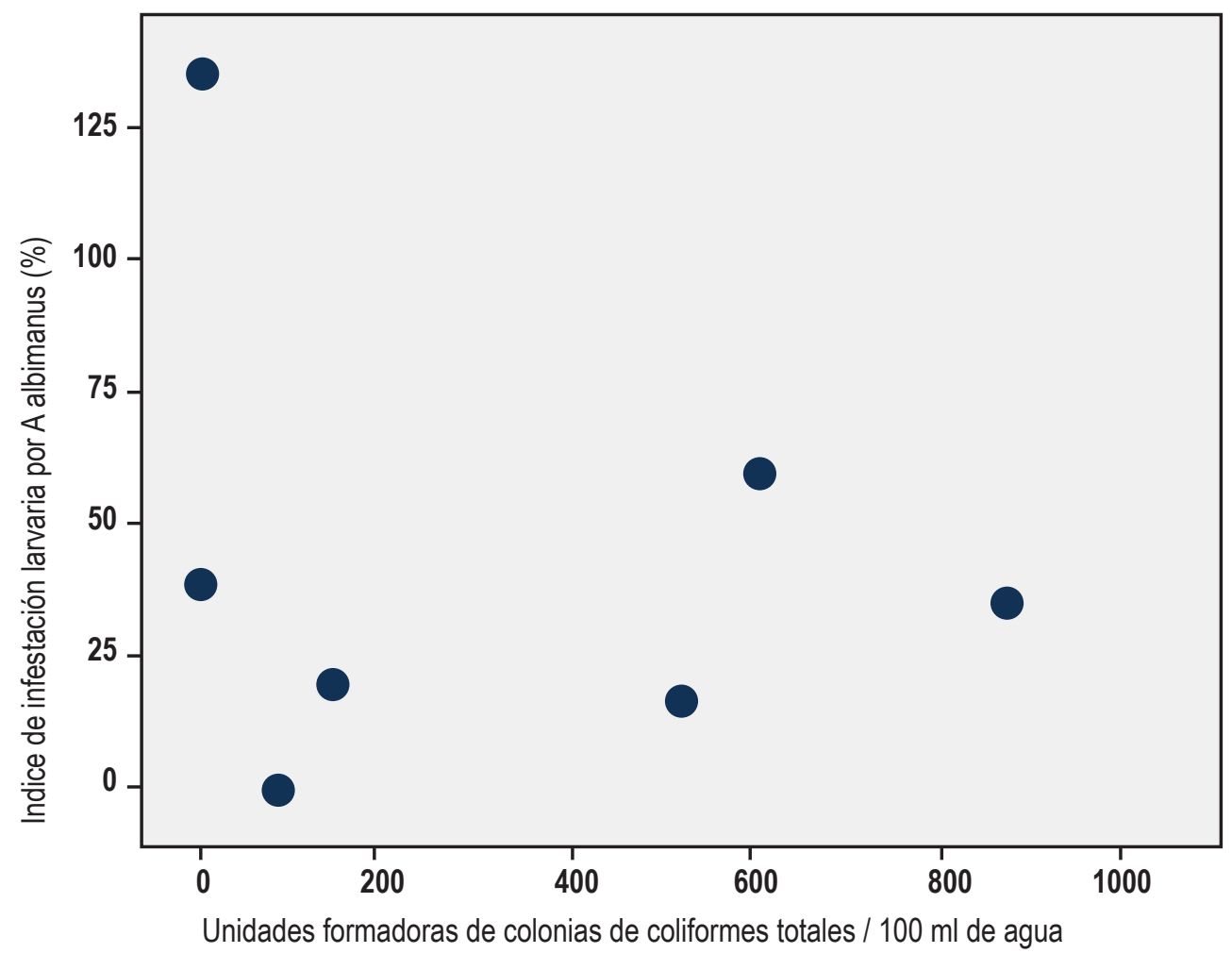

Fuente: hoja de resultados de programa estadístico SPSS (versión 18).

5. El gráfico 3 revela una dispersión de las correlaciones entre los datos del índice de infestación larvaria (\%) de Anopheles albimanus y el hallazgo de las unidades formadoras de Escherichia coli en las 8 lagunas monitoreadas en la presente investigación, lo que muestra que ya sea menor o mayor la contaminación por esta bacteria, los índices de infestación larvaria por Anopheles albimanus (menor del $75 \%$ ) se comportan de manera no relacional a la primera. 
Tabla 1. Coeficiente de correlación de Pearson ( $r$ ) entre el índice de infestación larvaria por Anopheles albimanus de las lagunas investigadas y la contaminación microbiológica por coliformes, septiembre de 2011

Parámetro microbiológico ( U.F.C / $100 \mathrm{ml}$ )
Correlación de Pearson (r) con los índices de infestación larvaria por A. albimanus (\%)

Coliformes totales

0.046

Coliformes fecales

$-0.014$

Escherichia coli

$-0.163$

Fuente: hoja de resultados de programa estadístico SPSS (versión 18).

*UFC: unidades formadoras de colonias por $100 \mathrm{ml}$ de agua.

6. En la tabla 1 se muestra que la correlación de Pearson ( $r$ ) entre el parámetro coliformes totales y el índice de infestación larvaria por Anopheles albimanus es de 0.046 , lo que en términos estadísticos significa que no existe relación alguna entre las variables anteriormente mencionadas.

7. En la tabla 1 se muestra que la correlación de Pearson ( $r$ ) entre el parámetro coliformes fecales y el índice de infestación larvaria por Anopheles albimanus es de -0.014 , lo que en términos estadísticos significa que no existe relación alguna entre las variables anteriormente mencionadas.

8. En la tabla 1 se muestra que la correlación de Pearson ( $r$ ) entre el parámetro coliformes totales y el índice de infestación larvaria por Anopheles albimanus es de -0.163 , lo que en términos estadísticos significa que no existe relación alguna entre las variables anteriormente mencionadas.

\section{DISCUSIÓN}

De forma importante la presente investigación demuestra mediante laboratorio una alta contaminación bacteriológica de las aguas usadas para la irrigación. Asimismo, revelan una creciente degradación microbiana de las fuentes que las alimentan, como los ríos, pues estos al pasar por los grupos poblacionales (aldeas, ciudades, etc.) reciben, sin ningún tratamiento, los residuos domésticos generados por sus habitantes. 
El índice de infestación resultante en una de las lagunas investigadas fue de más del $100 \%$, hallazgo alarmante desde el punto de vista epidemiológico.

Se demuestra que no existe coincidencia entre el mayor índice de infestación larvaria por Anopheles albimanus y los hallazgos mayores de coliformes totales, elemento contrario a lo que se esperaba encontrar en esta investigación. Es decir, no se encontró relación directamente proporcional entre estas dos variables, puesto que se determina más bien la relación inversamente proporcional de las mismas.

Se describe la coincidencia en el hallazgo del menor índice de infestación larvaria por Anopheles albimanus (0\%), con la menor cantidad de coliformes totales encontradas en las lagunas investigadas.

Se revela la dispersión de las correlaciones entre los datos del índice de infestación larvaria (\%) de Anopheles albimanus y el hallazgo de las unidades formadoras de colonias de coliformes totales en las 8 lagunas monitoreadas en la presente investigación, lo que s muestra en forma general que no existe una relación directa entre las dos variables anteriormente mencionadas.

Tomando en cuenta que el hallazgo de que los coliformes fecales se refiere a la presencia de materia orgánica de origen animal de sangre caliente, esto permite suponer la relación negativa que pudiese provocar el incremento de este elemento del agua en el ciclo biológico del vector investigado.

Se describe que coincide el hallazgo del menor índice de infestación larvaria por Anopheles albimanus (0\%), con la menor cantidad de coliformes fecales encontradas. Tomando en cuenta que el hallazgo de los coliformes fecales se refiere a la presencia de materia orgánica de origen de animal de sangre caliente, esto permite suponer la relación positiva que pudiese provocar la disminución de este elemento del agua en el ciclo biológico del vector investigado.

Los resultados laboratoriales en 3 lagunas monitoreadas (1, 2 y 4), muestran que la contaminación por Escherichia coli es mayor a 400 unidades formadoras de colonias por $100 \mathrm{ml}$ de agua, datos que no coinciden con el mayor índice de infestación larvaria por Anopheles albimanus, que estos mismos cuerpos de agua presentaron.

Se describe que no coincide el hallazgo del menor índice de infestación larvaria por Anopheles albimanus (0\%), con la menor cantidad de Escherichia coli encontradas en las lagunas investigadas. 
Se revela una dispersión de las correlaciones entre los datos del índice de infestación larvaria (\%) de Anopheles albimanus y el hallazgo de las unidades formadoras de colonias de Escherichia coli en las 8 lagunas monitoreadas en la presente investigación, lo que muestra que ya sea menor o mayor la contaminación por esta bacteria, los índices de infestación larvaria por Anopheles albimanus (menor del $75 \%$ ) se comportan de manera no relacional a la primera.

\section{CONCLUSIONES}

1. No hay correlación entre las variables analizadas en el presente estudio, esto comprueba el hecho de que existen otros factores en el agua que no formaron parte de esta investigación (salinidad, pluviosidad, sombra, luz, etc.), pero que sí intervienen en el ciclo biológico del mosquito Anopheles albimanus.

2. La alta incidencia de bacterias que constituyen el grupo de coliformes fecales y específicamente la Escherichia coli, tienen un efecto negativo sobre el ciclo biológico del Anopheles albimanus, presumiblemente por la acción de la producción de metabolitos de desecho (ácido como producto de la descomposición de los carbohidratos) que perjudican el desarrollo del vector investigado. Puede ser que estos grupos bacterianos sean sustratos alimenticios de los estadios larvarios del vector, pero su concentración excesiva afecta de una manera indeterminada (según los alcances de este estudio) el desarrollo del mosquito.

3. El hecho de que en el presente estudio no se demuestre la relación estadística a través del coeficiente de Pearson ( $r$ ) entre las variables estudiadas, no significa que pudiesen 0 no existir elementos de causalidad entre las variables estudiadas.

4. Con los elementos esgrimidos en el marco teórico de esta investigación, se puede concluir que la contaminación microbiológica en los cuerpos de agua en donde las larvas del mosquito Anopheles albimanus se desarrolla, está interfiriendo en forma negativa en el ciclo biológico de este vector. Esto comprueba, de cierta manera, el mecanismo de control biológico por Bacillus thurigiencis (BTI) sobre las larvas del A. albimanus. 
5. La contaminación de los cuerpos de agua superficiales (ríos, lagos, lagunas, etc.) revela un impacto negativo sobre el desarrollo humano desde el punto de vista de la equidad.

6. Es necesario, para poder determinar relaciones de causalidad con la variable índice de infestación larvaria por Anopheles albimanus, que se incorporen otras variables que no forman parte del presente estudio.

\section{RECOMENDACIONES}

1. Es necesaria la implementación y el fortalecimiento de políticas públicas que permitan evitar el deterioro de los entornos humanos, sin perjudicar el desarrollo de los mismos.

2. La vigilancia entomológica en la transmisión de la malaria en nuestro país, no ha sido considerada como una herramienta importante en la toma de decisiones para la formulación de políticas públicas que evidencien los riesgos de las poblaciones en donde se hace uso de cuerpos de agua para su desarrollo económico. Por lo tanto, es necesario no solamente el fortalecimiento de estas unidades entomológicas al interior de la Secretaría de Salud, sino también que sus recomendaciones tengan el apoyo político gerencial de la institución en el abordaje de las enfermedades transmitidas por vectores (ETV).

3. Se recomienda hacer un estudio longitudinal de cohorte que pudiese abarcar diferentes estaciones del año, ya que esto permitiría convalidar lo que la presente investigación ha inferido con un análisis transversal.

\section{AGRADECIMIENTO}

A todo el personal de la Región Sanitaria Departamental de Comayagua y del Centro Regional Universitario del Centro (CURC) por la colaboración brindada en el desarrollo de esta investigación. 


\section{BIBLIOGRAFÍA}

Agencia Sueca de Cooperación Internacional para el Desarrollo/ Sistema de Naciones Unidas / Gobierno de Honduras. (2010). Tercer Informe de País. Objetivos de Desarrollo del Milenio Honduras 2010. Tegucigalpa: X Media.

Bejarano, Eduar E. (2003). Occurrence of the malaria vector Anopheles albimanus Wiedemman (díptera: Culicidae) in Isla Fuerte, Colombia. Neo tropical Entomolgy, 32(3), 517-518.

Botero, L.; Zambrano, J.L.; Oliveros, C.; León, D.; Sarcos, M. y Martínez, M. (2002). Calidad microbiológica del agua de un sistema de lagunas de estabilización a ser empleada en la irrigación. Revista de facultad de Agronomía, 19, 312-323.

Forattini, Oswaldo Paulo y Brito, Marylene. (2003). Population dynamics of Aedes aegypti in an urban area with high incidence of Dengue. Revista de Salud Pública, 37(5), 676-7.

Guerra, Jorge Augusto. (2009). Aedes aegypti and associated fauna in the rural zone of Manaus, in the Brazilian Amazon. Revista de la Sociedad Brasileña de Medicina Tropical. 42(2), 213-216.

Korstanje, Maximiliano. (2010). Economía del riesgo, un análisis crítico a la mirada de Ulrich Beck. Economía, Sociedad y Territorio, X(32), 275-281.

McMichael, A. J.; Neira, M.; Bertollini, R.; Campbell-Lendrun, D. y Hales, S. (2009). Climate change: a time of need and opportunity for the health sector. The Lancet, 374, 2123-25.

Nunes Serpa, Ligia Leandro; Barbosa, Monteiro; Simone, D Cara y Voltolini, Julio César. (2008). Effect of larval rearing water on Aedes aegypti oviposition in the laboratory. Revista de la Sociedad Brasileña de Medicina Tropical, 41(5), 515-517.

Quintero, Juliana; Carrasquilla, Gabriel; Suárez, Roberto; Gonzales, Catalina y Olano, Víctor. (2009). Ecosystemic approach to evaluating ecological, socioeconomic and group dynamics affecting the prevalence of Aedes aegypti in two Colombian towns. Revista de Salud Pública, 25(1), 93-103. Río Janeiro.

Rodríguez Velásquez, Javier Oswaldo. (2010). Método para la predicción de la dinámica temporal de la malaria en los municipios de Colombia. Revista Panameña de Salud Pública, 27(3), 211-8.

Secretaría de Salud de la República de Honduras. (2005). Manual técnico operativo de salud ambiental. Tegucigalpa.

Secretaría de Salud de la República de Honduras. (2007). Compendio de claves taxonómicas en entomología para Centroamérica y Panamá. Tegucigalpa. 
Valdés Miro, Vivian y Marquetti Fernández, María del Carmen. (2010). Densidad larval y distribución espacio temporal de Anopheles albimanus (Díptera: Culicidae) en el municipio de Boyeros, 2008. Revista Cubana de Medicina Tropical, 62(2), 107-111.

Velásquez, Stella M. y Miserendino, M. Laura. (2003). Análisis de la materia orgánica alóctona y organización funcional de macro invertebrados en relación con el tipo de hábitat en ríos de montaña de Patagonia. Ecología Austral, 13, 67-82. 